\title{
Metabolic Deregulation Associated with Glycemic Imbalance In Gabonese Diabetics
}

\section{Guy-Stephane Padzys ${ }^{1}$, Joseph Privat Ondo ${ }^{3}$, Joseph Ndanga Tiagni ${ }^{1}$, Krystina Mengue Me Ngou-Milama ${ }^{2}$, Oriane Cordelia Aboumegone Biyogo $^{2}$, Amandine Mveang Nzoghe ${ }^{2}$, Agate Gorra ${ }^{4}$, Eric Baye ${ }^{4}$ and Joel Fleury Djoba Siawaya ${ }^{2 *}$}

${ }^{1}$ Département de Biologie Cellulaire et Physiologie Faculté des Sciences, Université des Sciences et Techniques de Masuku, BP 943, Franceville, Gabon ${ }^{2}$ Unités de Recherche et de Diagnostics Spécialisés, Laboratoire National de Santé Publique, BP. 10736, Libreville, Gabon

${ }^{3}$ Département de Chimie, Faculté des Sciences, Université des Sciences et Techniques de Masuku, BP 943 Franceville, Gabon

${ }^{4}$ Service d'Endocrinologie Centre Hospitalier Universitaire de Libreville, BP 2228, Libreville, Gabon

\begin{abstract}
Aim: Diabetes is a metabolic disease most often associated with complications when uncontrolled. The present study aimed to investigate the relationship between diabetes-associated complications, glycemic imbalances and other metabolic deregulation in Gabonese diabetics.

Methods: 115 known diabetics were recruited from the Libreville University hospital. We collected anthropometric data and information on associated pathologies. Blood samples collected were analyzed for blood glucose, urea, creatinine, triglycerides, cholesterol fractions and transaminases.

Results: Type-2 diabetes was more prevalent in the studied population, representing $90 \%$ of cased cases. $41.7 \%$ had diabetes cases were associated with hypertension alone. $9.6 \%$ of diabetes cases had kidney failure (associated or not with hypertension and/or neuropathy). $87 \%$ patients had uncontrolled blood sugar. Creatinine and urea were significantly higher in patients with affections as compared to patients without affections $(p<0.0001)$. In diabetics with controlled blood glucose concentration, only patients with the nephropathy had significantly high levels of creatinine and urea $(p<0.05)$. In diabetics with uncontrolled blood glucose concentration, significantly high levels of creatinine and urea were seen in both patients with hypertension and patient with nephropathy $(p<0.001)$
\end{abstract}

Conclusion: The high rate of hypertension and hyperglycemia observed suggest that Gabonese diabetics are at high risk for developing nephropathies.

Keywords: Diabetes; Hypertension; Nephropathy; Creatinine; Urea

\section{Introduction}

Diabetes is a serious threatening metabolic disease; it is manifested by accumulation of blood sugar also called hyperglycemia. The latter can affect organs such as the eyes, kidneys, the liver, heart and blood vessels, and lead to diabetes complications. It exists two types of diabetes. The immune system is in the core of the mechanisms leading to the development of both forms of diabetes. In type one (1) diabetes T-cellmediated autoimmune response against beta cells appears to be the main cause for the loss of the insulin-producing beta cells leading to insulin deficiency [1]. In type two (2) diabetes obesity related pro-inflammatory response is involved in the development of insulin resistance $[2,3]$.

Diabetes and its complications (Cardiovascular disease, nephropathy, neuropathy and retinopathy) are rising rapidly in Africa [4-7]. The International Diabetes Federation (IDF, 2015) estimated at 415 million, the number of diabetics worldwide, including 14.2 million in sub-Saharan Africa, and that number could reach 642 million worldwide, and 34.2 million sub-Saharan Africa by 2040 [8]. The continent westernization of lifestyle has markedly increased the prevalence of diabetes, making it, a relevant public health challenge $[5,9]$. A review highlighting diabetes complication reported that $15 \%$ to $55 \%$ are affected by retinopathy; between $5 \%$ to $15 \%$ are affected by coronary heart disease, cerebrovascular accidents and stroke [5].

In Gabon, the prevalence of diabetes increased from $0.3 \%$ in 1990 [10] to around $6 \%$ to $8 \%$ in 2015 [8,11], making it now the sixth country in Africa most affected by this disease. Poor metabolic control is a huge problem in Africa. The present study was undertaken to investigate the relationship between glycemic imbalances, other metabolic deregulation and diabetes complications in Adults Gabonese.

\section{Materials and Methods}

From August 2015 to January 2016, 115 known diabetics, patients with and without complications were recruited from the Libreville University hospital (CHUL) Endocrinology Center. For each patient, we recorded anthropometric data (name, gender, weight, height, age, sex, body mass index) and the characteristics of diabetes (type, age of discovery, seniority), associated complications and pathologies (renal complication, hypertension blood, arterial disease, nephropathy and neuropathy).

Blood samples were collected (after 12 hours fasting) in oxalate fluoride, heparin lithium and dry tubes. After centrifugation (3500 $\mathrm{tr} / \mathrm{min}$ for $15 \mathrm{~min}$ ), samples were analyzed for blood glucose, urea, creatinine, triglycerides, cholesterol, high-density lipoprotein (HDL), low-density lipoprotein (LDL) and transaminases (ASAT and ALT) using the SB-200 Mindray Analyzer (Shenzhen, China). We also looked at sodium $\left(\mathrm{Na}^{+}\right)$, potassium $\left(\mathrm{K}^{+}\right)$, chloride $\left(\mathrm{Cl}^{-}\right)$and bicarbonate $\left(\mathrm{HCO}_{3}^{-}\right)$ion concentrations [Audicom AC9900 (Jiangsu, China)]. All participants consented to the study, which was approved by the National Laboratory board.

*Corresponding author: Joel Fleury Djoba Siawaya, Unités de Recherche et de Diagnostics Spécialisés, Laboratoire National de Santé Publique, B.P. 10736, Libreville, Gabon, Tel: +24106081715; E-mail: joel.djoba@gmail.com

Received: June 05, 2017; Accepted: June 20, 2017; Published: June 24, 2017

Citation: Padzys G, Ondo JP, Tiagni JN, Ngou-Milama KMM, Biyogo OCA, et al. (2017) Metabolic Deregulation Associated with Glycemic Imbalance In Gabonese Diabetics. Diabetes Case Rep 2: 125. doi: 10.4172/2572-5629.1000125

Copyright: $\odot 2017$ Padzys G, et al. This is an open-access article distributed unde the terms of the Creative Commons Attribution License, which permits unrestricted use, distribution, and reproduction in any medium, provided the original author and source are credited. 
The difference between patients with affections and patients without affections was analysed using the Mann-Whitney U-tests. The impact of high blood pressure and nephropathy on biochemical parameters within the groups of patients of diabetics with and without normal blood glucose concentration were analyzed using the Kruskal-Wallis multiple comparison test and Dunn's post-test. For all tests, a p-value below $5 \%$ was considered significant.

\section{Results and Discussion}

Of the 115 enrolled diabetic patients, 21 were men (18.3\%) and 94 women (81.7\%) (Female to male sex ratio of 4.52). Patients' anthropometric characteristics are reported in Table 1. About $10 \%$ (11 patients) of cases had type-1 diabetes. Type-2 diabetes was more prevalent in the studied population, representing $90 \%$ of cases (104 patients). This is not surprising as studies showed that the burden of diabetes in Africa is driven by type -2 diabetes [5], which has markedly increased due to urbanization and the change in lifestyle [5]. Nearly half $(47.8 \%)$ of diabetics had associated affections. $41.7 \%$ had diabetes cases were associated with hypertension alone. 9.6\% of diabetes cases had kidney failure (associated with hypertension and/or neuropathy). Hypertension was the most prevalent condition in our diabetics (50.4\%). The same was shown in Nigeria [12], although the Nigerian study showed a higher rate of hypertension (60.9\%). In Europe and Asia the prevalence of hypertension in diabetics was shown to be above $70 \%$ [13], which is also higher compared to what we found. The literature shows that high rates of microvascular complications in diabetics can be attributed to frequent high blood pressure [5]. $0.9 \%$ of cases had diabetes associated with neuropathy alone (Table 2 ). We previously reported that the incidence of hyperglycemia in a sampled population of Libreville (Gabon) was 5.8\% [11]. We also showed that in this sample of the population the frequency of the combination hyperglycemia and hypertension was $10.5 \%$ [11]. Altogether this shows that the association between diabetes or hyperglycemia and hypertension is more prevalent in known diabetics, which is expected.

Patients who had their blood sugar under control represented only $13 \%$ of all patients. Uncontrolled blood sugar level was observed in $87 \%$ of the studied population. The study done by Uloko et al., in Nigeria reported similar findings [12], suggesting that most African diabetics have suboptimal glycemic control and are hypertensive. The rate of diabetes-associated affections or pathologies was $49 \%$ (49 out of 100)

\begin{tabular}{|c|c|c|}
\hline Parameters & Male & Female \\
\hline Age (years) & $51.04 \pm 13.81$ & $54.95 \pm 19.35$ \\
\hline Weight $(\mathrm{Kg})$ & $67 \pm 19.28$ & $68.07 \pm 16.37$ \\
\hline Height $(\mathrm{m})$ & $1.66 \pm 0.07$ & $1.6 \pm 0.09$ \\
\hline BMI & $24.22 \pm 7.61$ & $26.14 \pm 5.7$ \\
\hline Diabetes age (months) & $42 \pm 54.05$ & $81 \pm 101.44$ \\
\hline
\end{tabular}

Table 1: Anthropometric parameters of the study population.

\begin{tabular}{|l|c|c|c|c|}
\hline \multirow{2}{*}{ Pathologies/Affections } & \multicolumn{2}{|c|}{ Gender } & \multirow{2}{*}{ Total } & \multirow{2}{*}{ Percentage } \\
\cline { 2 - 4 } & Male & Female & & \\
\hline Diabetes & 8 & 47 & 55 & $47.8 \%$ \\
\hline Diabetes + HT & 11 & 37 & 48 & $41.7 \%$ \\
\hline Diabetes + HT + KF & 1 & 8 & 9 & $7.8 \%$ \\
\hline Diabetes + HT + KF + Neuro & 0 & 1 & 1 & $0.9 \%$ \\
\hline Diabetes + KF + Neuro & 1 & 0 & 1 & $0.9 \%$ \\
\hline Diabetes + Neuro & 0 & 1 & 1 & $0.9 \%$ \\
\hline Total & 21 & 94 & 115 & $100.0 \%$ \\
\hline
\end{tabular}

HT: Hypertension; Neuro: Neuropathy; KF: Kidney Failure

Table 2: Distribution of diabetes cases based on associated conditions.
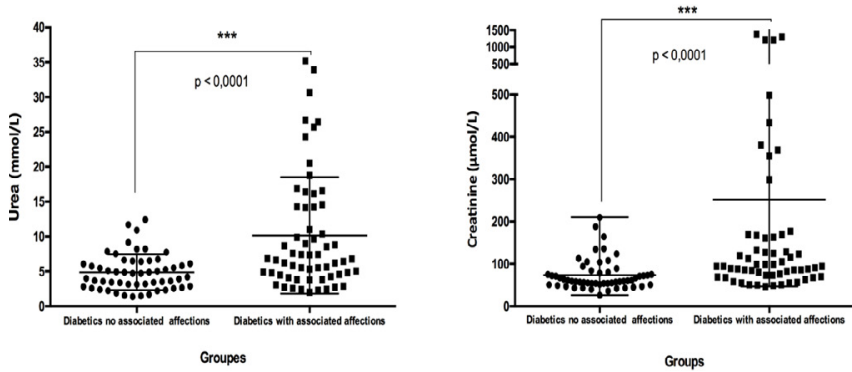

Figure 1: Serum concentration levels of creatinine and urea in diabetics with and without associated medical conditions. Diabetics with other associated medical conditions had significantly higher concentration of both creatinine and urea than diabetics with no other medical conditions $(p<0.0001$, MannWhitney U-tests).

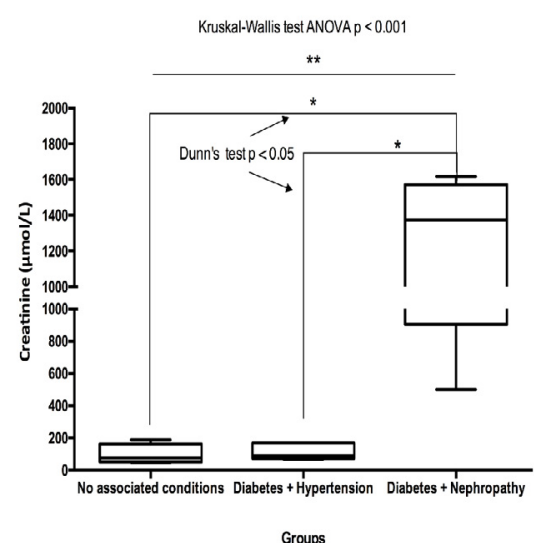

Figure 2: Creatinine concentration associated with the type of observed medical conditions in diabetics with normal blood glucose levels. Only diabetics with nephropathies showed significantly higher concentration of creatinine as compared to diabetics with hypertension and diabetics with no associated medical conditions ( $p<0.05$, Dunn's post-test).

in patients with uncontrolled blood sugar levels and 73\% in patients with normal blood glucose levels (11 out of 15$)$. The very small number of patients with normal or controlled levels of blood glucose gives small meaning to the rate of diabetes-associated affections and their impact on biochemical parameters in this group. Also, glycated hemoglobin (HbA1C) would have been a better marker for uncontrolled glycaemia in diabetics. Therefore, the absence of HbAlC assessment is a limit of our study.

All patients considered, creatinine and urea were significantly higher in patients with affections as compared to patients without affections $(\mathrm{p}<0.0001)$ (Figure 1). No significant differences were in the levels of: triglycerides, cholesterol (all types), transaminases, $\mathrm{Na}^{+}$, $\mathrm{K}^{+}, \mathrm{Cl}^{-}$, and $\mathrm{HCO}_{3}^{-}$. When only patients with uncontrolled blood sugar level was analyzed, exactly the result was found. This is not surprising as these patients represented nearly $90 \%$ of the studied population. In patients with normal blood glucose concentration, the high levels of creatinine and urea observed in patients with affections were driven by nephropathies $(\mathrm{p}<0.05)$ (Figures 2 and 3 ), whereas patients with uncontrolled blood glucose significantly high levels of creatinine and urea were observed in both patients with hypertension (no nephropathy) and patient with nephropathy $(\mathrm{p}<0.001)$ (Figures 4 and 5). The fact that urea and creatinine were significantly higher in diabetics with associated affections is not that surprising, as the impact diabetes disease and hypertension on kidney function is well established [14-18]. One interesting observation is that uncontrolled 
Citation: Padzys G, Ondo JP, Tiagni JN, Ngou-Milama KMM, Biyogo OCA, et al. (2017) Metabolic Deregulation Associated with Glycemic Imbalance In Gabonese Diabetics. Diabetes Case Rep 2: 125. doi: 10.4172/2572-5629.1000125

Page 3 of 4

blood glucose levels associated with hypertension significantly strained kidney function as shown by the Figures 4 and 5, thereby increasing the risk of nephropathy [19-21]. Altogether, the high rate of hypertension and hyperglycemia in the sampled diabetic population suggests that Gabonese diabetics are at high risk for developing nephropathies.

This study showed type-2 diabetes to be more prevalent. However, the study is limited by the fact that in our setting, ketosis-prone atypical diabetes 2 , which resembles diabetes type 2 and is characterized by a specific insulin-secretion defect and suboptimal insulin action, could not be diagnosed. Whereas this form of diabetes under diagnosed, in the African population is thought to be more prevalent [22].

\section{Conclusion}

Hypertension and uncontrolled glycaemia in African diabetics are factors exacerbating the disease, and affecting African diabetics quality of life. African practitioners should emphasize this aspect to their patients to increase patients' awareness and reduce the morbidity of this disease.

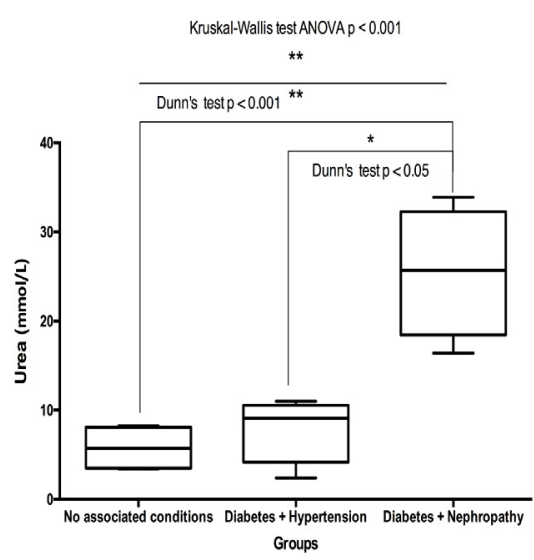

Figure 3: Urea concentration associated with the type of observed medical conditions in diabetics with normal blood glucose levels. Only diabetics with nephropathies showed significantly higher concentration of Urea as compared to diabetics with hypertension $(p<0.05)$ and diabetics with no associated medical conditions ( $p<0.001$, Dunn's post-test).

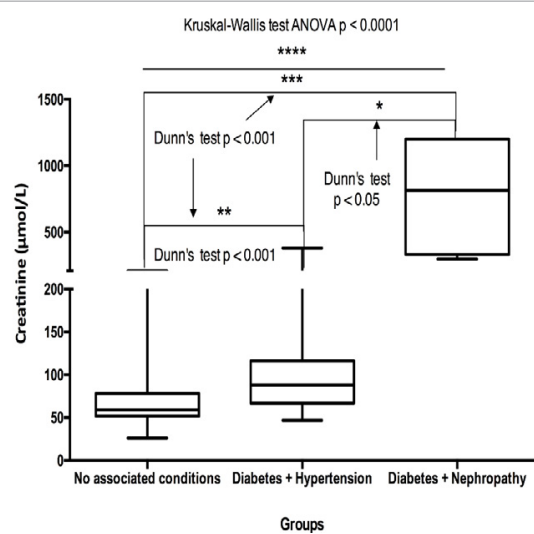

Figure 4: Creatinine concentration associated with the type of observed medical conditions in diabetics with uncontrolled blood glucose levels. Diabetics with hypertension and diabetics with nephropathies showed significantly higher concentration of creatinine as compared to diabetics with no associated medical conditions ( $p<0.001$, Dunn's post-test). Diabetics with nephropathies showed significantly higher concentration of creatinine as compared to diabetics with hypertension ( $p<0.05$, Dunn's post-test).

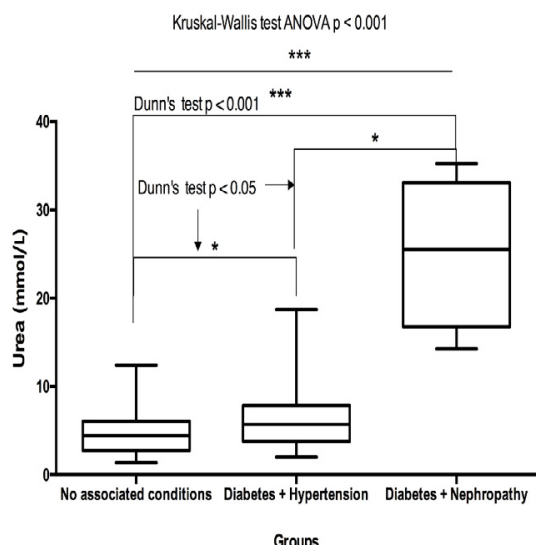

Figure 5: Urea concentration associated with the type of observed medical conditions in diabetics with uncontrolled blood glucose levels. Diabetics with hypertension and diabetics with nephropathies showed significantly higher concentration of urea as compared to diabetics with no associated medical conditions (respectively $p<0.05$ and $p<0.001$, Dunn's post-test). Diabetics with nephropathies showed significantly higher concentration of urea as compared to diabetics with hypertension ( $p<0.05$, Dunn's post-test)

\section{Acknowledgement}

We would like to thank to all patients who were included in the study and acknowledge the involvement of the Libreville University Hospital Endocrinology and Laboratory Service workers. The "Unités de Recherche et de Diagnostics Spécialisés, Laboratoire National de Santé Publique, Gabon" Funded the study.

\section{Conflict of Interest}

All authors have seen and approved the manuscript and declare that they have no competing interests." Also, no financial or other competing interests exist.

\section{References}

1. Xie Z, Chang C, Zhou Z (2014) Molecular mechanisms in autoimmune type 1 diabetes: A critical review. Clin Rev Allergy Immunol 47: 174-192.

2. Qatanani M, Lazar MA (2007) Mechanisms of obesity-associated insulin resistance: Many choices on the menu. Genes Dev 21: 1443-1455.

3. Donath MY, Shoelson SE (2011) Type 2 diabetes as an inflammatory disease. Nat Rev Immunol 11: 98-107.

4. Assayed A (2013) Diabetes in Africa: The dark tunnel. African Journal of Diabetes Medicine 21: 4-5.

5. Mbanya JC, Motala AA, Sobngwi E, Assah FK, Enoru ST (2010) Diabetes in sub-Saharan Africa. Lancet 375: 2254-2266.

6. Motala AA, Omar MA, Pirie FJ (2003) Diabetes in Africa. Epidemiology of type 1 and type 2 diabetes in Africa. J Cardiovasc Risk 10: 77-83.

7. Peer N, Kengne AP, Motala AA, Mbanya JC (2014) Diabetes in the Africa Region: An update. Diabetes Res Clin Pract 103: 197-205.

8. Federation ID. Diabetes Atlas. 2015

9. Motala AA (2002) Diabetes trends in Africa. Diabetes Metab Res Rev 18: S14-20.

10. Ntyonga-Pono MP, Nguemby-Mbina C (1996) Le diabète sucre à Libreville prévalence et perspectives. Med Afr Noire 43(7): 430-433.

11. Djoba Siawaya JF, Bakimbi Mombo R, Nguema Obame Abessolo AS, Alame Emane AK, Kouegnigan Rerambiah L (2015) Prevalence and Relationship between Hyperglycemia Hypertension and Obesity in Libreville-Gabon: A Pilot Study. Endocrinol Diabetes Res 1: 1-3.

12. Uloko AE, Ofoegbu EN, Chinenye S (2012) Profile of Nigerians with diabetes mellitus - Diabcare Nigeria study group (2008): Results of a multicenter study. Indian J Endocrinol Metab. 16(4): 558-564

13. Colosia AD, Palencia R, Khan S (2013) Prevalence of hypertension and obesity in patients with type 2 diabetes mellitus in observational studies: a systematic literature review. Diabetes Metab Syndr Obes 6: 327-338. 
Citation: Padzys G, Ondo JP, Tiagni JN, Ngou-Milama KMM, Biyogo OCA, et al. (2017) Metabolic Deregulation Associated with Glycemic Imbalance In Gabonese Diabetics. Diabetes Case Rep 2: 125. doi: 10.4172/2572-5629.1000125

14. Gnudi L (2016) Angiopoietins and diabetic nephropathy. Diabetologia 59: 1616-1620.

15. Zheng S, Powell DW, Zheng F, Kantharidis P, Gnudi L (2016) Diabetic Nephropathy: Proteinuria, Inflammation, and Fibrosis. J Diabetes Res 2016: 5241549.

16. Montero RM, Covic A, Gnudi L, Goldsmith D (2016) Diabetic nephropathy: What does the future hold? Int Urol Nephrol 48 : 99-113.

17. Karalliedde J, Gnudi L (2016) Diabetes mellitus, a complex and heterogeneous disease, and the role of insulin resistance as a determinant of diabetic kidney disease. Nephrol Dial Transplant 31: 206-213.
18. Lago RM, Singh PP, Nesto RW (2007) Diabetes and hypertension. Nat Clin Pract Endocrinol Metab 3: 667.

19. Steigerwalt S (2008) Management of Hypertension in Diabetic Patients With Chronic Kidney Disease. Diabetes Spectrum 21: 30-36.

20. Ravera M, Re M, Deferrari L, Vettoretti S, Deferrari G (2006) Importance of blood pressure control in chronic kidney disease. J Am Soc Nephrol 17 : S98-103.

21. Hall MP (2006) Prevention of Progression in Diabetic Nephropathy. Diabetes Spectrum 19: 18-24.

22. Gill G (2014) Diabetes in Africa - Puzzles and challenges. Indian J Endocrinol Metab 18: 249-251. 